\title{
10. Navigating a Nuclear Past Where Archives Are Missing
}

\section{Marissa Bell}

Marissa Bell is a Postdoctoral Associate in the Department of Communication at Cornell University. She holds a PhD in Geography from the University of Buffalo. Marissa's approaches combine environmental justice, energy geography, and science and technology studies to critically examine community engagement in knowledge production and environmental decision-making, with long standing interest and expertise in nuclear waste policy and practices. marissa.bell@cornell.edu

\section{Situating Process in Spatio-temporal Context}

An outsider to geography might think of it as a discipline preoccupied with space, yet as geographers will attest to, the acknowledgement of the deep interconnection between space and time, otherwise theorized as space-time, is what strengthens the perspective while drawing from across disciplines. ${ }^{1}$ In-depth examinations of the geographic context of various phenomena are incomplete without looking back in time at how a place came to be, situating an understanding of the place in historic context. The nuclear geographies literature, to which this work contributes, is strengthened and grounded by perspectives which embed themselves in space-time (e.g. see Karen Bickerstaff's work). ${ }^{2}$ The question then becomes how to access the past. Through what mechanisms can we access the details of structures, processes, and institutions that have influenced what is happening today? Archives are one incredibly important component that scholars from across disciplines have relied on to extract information from the past. I will note here that my use of the term "archive" may differ from an historian's use. Rather than focus on the archive as an institution, I focus on archives as an 
accumulation of knowledge and information situated across physical and digital spaces, official and unofficial. Yet, even with this liberal definition of the archive, not all is contained within it. This short essay is a personal reflection on experiences of the contested nature of information contained within the past, where such archives do not unlock the secrets of the past, and where information is not contained within the bounds of archival institutions. The aim is to reevaluate archives from the perspective of gaps in archival institutions, and to begin to think about what challenges and opportunities the future may hold for archival research.

I begin by drawing upon experiences writing about a public health controversy surrounding radiation contamination in the town of Port Hope, Canada, with particular attention to how access to and control of information remains a contested issue. I then call for a reevaluation of what information ought to be valued in the archival format, suggesting an expansion to community histories, and perhaps reflecting on the heavy responsibility of archiving. In doing so, I finally offer some reflections on the "information age," and the dual struggles of accessing the right information (1) where an abundance of information exists (the needle in the haystack/tyranny of transparency), ${ }^{3}$ and (2) where the right information is everywhere but nowhere (fingers pointing) stemming from the questions surrounding the burden of responsibility. As historians have articulated far better than I ever could, there is a strong need for understanding the social, geographic, and political economic context of how we got to where we are today, such that we might learn from the past to inform future decisionmaking. 


\section{The Burden of Responsibility: Whose archive?}

As environmental justice scholars have noted, the burden of responsibility often falls to communities to prove contamination and exposure. ${ }^{4}$ While governments and corporations have some duty, the burden often comes to civil society to prove that harm has been done to justify action or reaction. The matter of nuclear waste contamination is further complicated when social and political controversies underlie investigations of harm.

In our study of Port Hope, my co-author, David Bell, and I sought to examine the public health controversy surrounding low-level radioactive waste contamination, focusing on the prolonged political and emotional sensitivity associated with the contamination. ${ }^{5}$ The work involved assessing the public health controversy around the unresolved scientific debate over contamination. This meant we poured over previous health studies conducted on this issue along with contextual secondary data, to understand the context of the study and their reception, focusing on scientific ambiguity and contestation, and questions of expertise and scientific authority surrounding opposing medical voices. Slowly the work became centered on one of the dominant stakeholders, a community advocacy organization, the Port Hope Community Health Concerns Committee (PHCHCC), who had raised critical questions concerning significant health studies that had been conducted by the Canadian Nuclear Safety Commission (CNSC) and Health Canada, the federal agencies responsible for ensuring health and nuclear safety through specified jurisdictions. The PHCHCC subsequently requested independent evaluations of those health studies conducted by CNSC and Health Canada. However, during the research, we encountered significant difficulties finding the data, the 
studies, and the reports and responses that were created and ostensibly made available.

Despite the studies being federally commissioned work, the reports were unavailable in official federal archives. We then turned to digital archival sources, again encountering significant challenges in finding the reports; one source would reference another source that would reference yet another source, leading to a wild goose chase in search of the golden egg not to be found. To this day, one of the studies commissioned by the CNSC in particular, for example, remains unpublished and unavailable, which at best is an oversight of mild incompetence, and at worst a deliberate suppression of evidence. From later private communication, we understood that key community stakeholders believed the latter. Together with other data points, other missing data, and institutional attitudes, the situation points to the latter as the basis for distrust and socio-political controversy. The difficulty is that in this age of digital dominance, intentionality can be masked by technical incompetence, error and mishap, as it often is.

While many sources purported that the only remaining copy of the study remained "in the hands of the PHCHCC" who made it publicly available at the time, ${ }^{6}$ the broader point is that a publicly funded and publicly relevant study should continue to be widely available under the responsibility of the CNSC and Health Canada, at the very least in digital archives. The fact that the access to this study must rely on a civic advocacy group, such as $\mathrm{PHCHCC}$, archiving relevant public health data and upholding principles of transparency, shifts the burden of responsibility away from federal and corporate actors again to civil society, reflecting the broader institutional burden on communities. This shift in responsibility puts pressure on civil society in 
problematic ways and points to the need for broader accountability of archival work in regulated ways. Some of this work continues to be within the purview of public domain, particularly in the information age, which I turn to next.

The Information Age: Where is the Archive?

Technology has indeed transformed the way we relate to information, particularly in the context of working with archives of various forms. One of the significant challenges scholars face is the overwhelming abundance of information existing within a complex convoluted and dynamic digital internet space. Here, there is a need for emphasis on the nature of and difference between digitized versus digital archives. Both digitized and digital archives can rely on computer information systems and be stored online, with the difference being that digitized archives are still within the scope of archival institutional bounds, whereas digital archives need not be, thus the latter is far more widespread and complex to navigate. Within this disorganized internet space sources can hyperlink to other sources and the original source may be misplaced, mis-linked, lost or even non-existent. Strategies can be utilized, such as Boolean search functions and reliance on databases to search for these missing sources, but sometimes the information is simply somewhere on the web and cannot be accessed as there is no hyperlink pathway, or it is completely lost or non-existent. With this abundance of information, it can be difficult to follow the leads and find the information needed. Yet, in the age of transparency and accountability, this abundance can be deliberately produced to make finding the right information next to impossible, something that has been referred to as the tyranny of transparency. ${ }^{7}$ When it comes to multiple stakeholders and federal actors responsible, the 
opportunity for the obfuscation of responsibility arises, with the directing of attention to alternate actors whose responsibility it might have been to store and make accessible the information. This perceived tyranny of transparency is demonstrated in other informational contexts. In my more recent research on nuclear waste siting in Canada, ${ }^{8}$ community stakeholders and advocates perceived the abundance of information as a barrier to being properly informed, with the "overwhelming" "reams and reams" of information, much of it repeating itself from year to year, with residents feeling "snowed under." This is a challenge that needs to be addressed in the coming decades.

The role of the digital platform is complex and presents both challenges and opportunities. The storage platforms present the challenges of an abundance of disorganized data, technically available but not always practically accessible. However, at the same time, there are opportunities for vast quantities of data to be stored, and there are also possibilities for long-term archiving of materials. Many of the hyperlinks referenced in the Port Hope study are likely to be non-functioning by now, often through websites getting updated or shifting their organizational structure. This presents opportunity for internet archival platforms, such as archive.com, the Wayback Machine, perma.cc, UK Web Archive, among others, to ground and make more permanent the ephemerality of the "hyperlink." Some of these are run by private institutions, other by public government or non-governmental institutions. The problem is that there is no standard for archiving, and the archives are inconsistent. Consequently, I argue for a revisiting of archival work, to reimagine how it might shift with the times, broadening in scope, and within a more organized and perhaps more regulated manner. 


\section{Reflections on the Future: Broadening Archival Scope}

While access to health studies and reports of a scientific nature may continue to be an issue, the Port Hope study also illuminated the ways in which there is a need to archive experiences and perspectives. Of course, these are captured in oral histories, but it is clear from this work, as well as other emerging issues (see for example the West Valley Demonstration Project) in which the oral histories are not being captured and there is a risk that decades of experience and expertise, belonging to members of the public and advocacy groups, may be lost to time. Consequently, I call for an emphasis on what ought to be valued in archival format and for more institutionalized focus on community and oral histories; this would shift the burden away from the communities already burdened with the effects of radioactive contamination to begin with.

The second note relates to the challenges and opportunities of online archival initiatives, from the proliferation of disorganized material to the opportunities for more organized and institutionalized archival work; these extend beyond the information storage and management, but also to potential training for how to utilize such archival sources. Expanding both the types of data that are emphasized in archival work and the ways we store and archive said work, will likely provide more promising prospects for better utilization of archival work. This is imperative for examining not only data produced in the past, but also the context in which it was produced. This could lead to more geographically-sensitive and temporallyinformed decision-making for being a more sustainable, just and equitable world. 


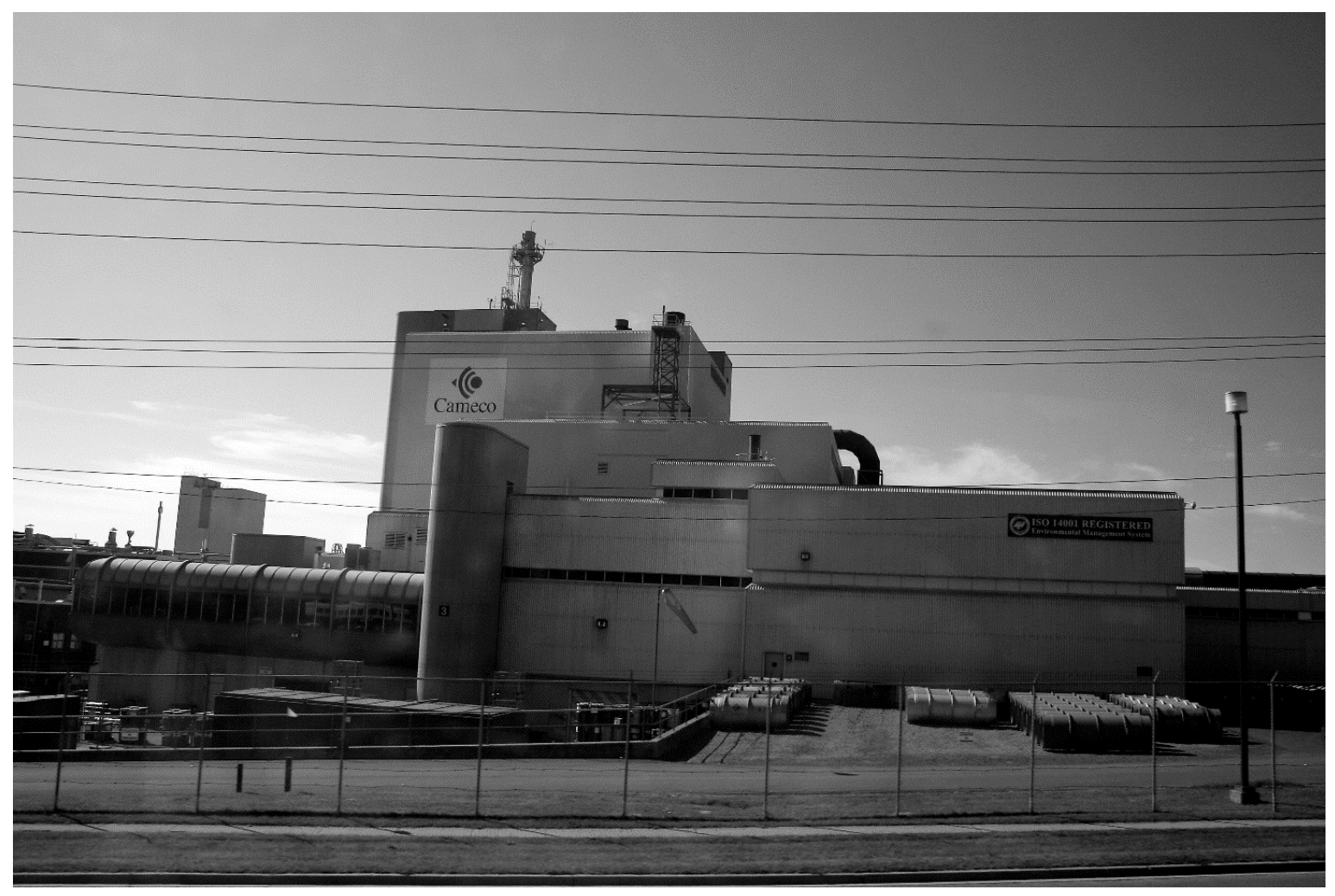

Figure 9. The oldest refinery of uranium in the world, Cameco, once known as Eldorado Mining and Refining Ltd., is located on the outskirts of the Town of Port Hope in Ontario, Canada. The facility processed and refined weapons-grade uranium, and in this process produced copious amounts of low-level waste that contaminated the local area. It is these activities that have been at the center of radioactive public health controversy in Port Hope, including controversies of transparency around the provision and access to data and studies. (Photographer Robert Taylor, Cameco Nuclear, Port Hope, Ontario_4715, June 20, 2011, https://www.flickr.com/photos/bobolink/5857844634/in/photostream/. Used under a CC BY 2.0 Generic license.)

${ }^{1}$ Doreen Massey, For Space (London: Sage, 2005), 61-74.

2 Karen Bickerstaff, "Because We've Got History Here: Nuclear Waste, Cooperative Siting, and the Relational Geography of a Complex Issue," Environment and Planning A 44, no. 11 (2012): 2611-28.

${ }^{3}$ Aarti Gupta, "Transparency under Scrutiny: Information Disclosure in Global Environmental Governance," Global Environmental Politics 8, no. 2 (2008): 4. 
${ }^{4}$ Institute of Medicine Committee on Environmental Justice, "Toward Environmental Justice: Research, Education, and Health Policy Needs," (1999), vii.

${ }^{5}$ David Elijah Bell and Marissa Bell, "Port Hope Burning: The Trail of Eldorado, the Uranium Medical Research Centre, and Community Tension over Scientific Uncertainty," in Nuclear Portraits: Communities, the Environment, and Public Policy, ed. Laurel S. MacDowell (Toronto, CA: University of Toronto, 2017), 250.

${ }^{6}$ Bell and Bell, 250.

7 Marilyn Strathern, "The Tyranny of Transparency," British Educational Research Journal 26 , no. 3 (2000).

${ }^{8}$ Marissa Bell, "Energy Justice, Nuclear Landscapes, and Consent: An Examination of Canadian Nuclear Waste Siting," (University at Buffalo, SUNY, 2021), 230-231. 